\title{
The Application of Resonance Light Scattering Technique for the Determination of Tinidazole in Drugs
}

\author{
Xin Yu Jiang, ${ }^{1}$ Xiao Qing Chen, ${ }^{1}$ Zheng Dong, ${ }^{2}$ and Ming $\mathrm{Xu}^{3,4}$ \\ ${ }^{1}$ College of Chemistry and Chemical Engineering, Central South University, Changsha 410083, China \\ ${ }^{2}$ Hunan Wantwant Hospital, Changsha 410016, China \\ ${ }^{3}$ Research Institute for Molecular Pharmacology and Therapeutics, Central South University, Changsha 410083, China \\ ${ }^{4}$ Department of Radiation Oncology, Memorial Sloan-Kettering Cancer Center, New York, NY 10021, USA
}

Received 13 January 2007; Accepted 26 April 2007

\begin{abstract}
A resonance light scattering technique to determine tinidazole in drugs was developed by tetraphenylboron sodium (TPB). Tinidazole was found to bind $\mathrm{B}\left(\mathrm{C}_{6} \mathrm{H}_{5}\right)_{4}^{-}$anion and transformed to tinidazole-TPB aggregate which displayed intense resonance scattering light. Effects of factors such as wavelength, acidity, stabilizers, and interferents on the RLS of tinidazole TPB were investigated in detail. The RLS intensity of the tinidazole-TPB suspension was obtained in sulfuric acid solution $(\mathrm{pH}=1.44)$. The resonance scattering light intensity at the maximum RLS peak of $569.5 \mathrm{~nm}$ was linear to the concentration of tinidazole in the range of 10.0 $30.0 \mu \mathrm{g} \mathrm{mL}^{-1}$ with a detection limit of $5.0 \mu \mathrm{g} \mathrm{mL}^{-1}$. Good results were also obtained with the recovery range of $95.13-106.76 \%$. The method was applied to determine tinidazole in injections and tablets, showing high sensitivity and accuracy compared with the high performance liquid chromatography method (HPLC) according to Chinese Pharmacopoeia.
\end{abstract}

Copyright (c) 2007 Xin Yu Jiang et al. This is an open access article distributed under the Creative Commons Attribution License, which permits unrestricted use, distribution, and reproduction in any medium, provided the original work is properly cited.

\section{INTRODUCTION}

Tinidazole is chemically 1-(2-ethylsulfonyl-ethyl)-2-methyl5 -nitroimidazole (Figure 1). It is active against protozoa and anaerobic bacteria and is used like metronidazole in a range of infections [1]. The drug is reported to hydrolyze quantitatively in alkaline conditions to 2-methyl-5nitroimidazole and under photolytic conditions, the drug yields intermediate, rearrangement, and degradation products [2].

Resonance light scattering (RLS) is an elastic scattering and occurs when an incident beam in energy is close to an absorption band. Pasternack et al. first established the RLS technique to study the biological macromolecules by means of an ordinary fluorescence spectrometer [3-5]. Due to their high sensitivity, selectivity, and convenience, RLS studies have attracted great interest among researchers [6-10]. RLS has emerged as a very attractive technique that has been used to monitor molecular assemblies and characterize the extended aggregates of chromophores. In recent years, RLS technique has been used to determine pharmaceutical $[11,12]$ and various biological macromolecules such as nucleic acid $[13,14]$, protein [15, 16], metal ion [17], and bacteria [18], while the study and determination of tinidazole with RLS technique were not yet reported.
Several analytical methods for tinidazole have been developed so far such as HPLC [19], LC-MS [20], capillary electrophoresis [21], spectrophotometry [22], voltammetry [23], and electrochemical methods $[24,25]$. Among these analytical methods, the voltammetry method according to Chinese Pharmacopoeia is popular and regarded relatively reliable for the determination of tinidazole. Although it often provides very accurate results, it suffered from cost time and complexity. HPLC was also used to determine tinidazole in drugs in Chinese Pharmacopoeia with good result but needs tedious pretreatment.

Herein, we report a robust, quick, and simple method for the determination of tinidazole in injections and tablets with $\mathrm{NaB}\left(\mathrm{C}_{6} \mathrm{H}_{5}\right)_{4}$ as a probe by RLS technique. The obtained results were almost in agreement with those obtained by the currently used HPLC method according to Chinese Pharmacopoeia.

\section{EXPERIMENTAL}

\subsection{Apparatus}

RLS spectra were obtained by synchronous scanning in the wavelength region from 250 to $750 \mathrm{~nm}$ on a JASCO FP-6500 spectrofluorometer (Tokyo, Japan) using quartz cuvettes 


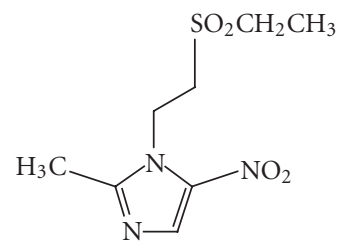

FIGURE 1: Structure of tinidazole.

$(1.0 \mathrm{~cm})$. The width of excitation and emission slits was set at $3.0 \mathrm{~nm}$. HPLC analysis was carried out on an Agilent 1100 HPLC system (USA) equipped with G1314A isocratic pump, a thermostatted column compartment, a variablewavelength UV detector (VWD), and Agilent ChemStation software. The $\mathrm{pH}$ measurements were carried out on a PHS$3 \mathrm{C}$ exact digital $\mathrm{pH}$ meter equipped with Phoenix $\mathrm{Ag}-\mathrm{AgCl}$ reference electrode (Cole-Palmer Instrument Co., Ill, USA), which was calibrated with standard $\mathrm{pH}$ buffer solutions.

\subsection{Reagents}

A working solution of tetraphenylboron sodium (10.0 $\mathrm{mg} \mathrm{mL} \mathrm{mL}^{-1}$ ) was prepared with methanol-water solution (20 : $80, \mathrm{v} / \mathrm{v})$. A stock solution of tinidazole was prepared by dissolving tinidazole ( $>99.99 \%$, Sigma) in the doubly distilled water. The working solutions of tinidazole were obtained by diluting the stock solution prior to use. Sulfuric acid solution $\left(0.18 \mathrm{~mol} \mathrm{~L}^{-1}\right)$ was used to control the acidity, while $0.1 \mathrm{~mol} \mathrm{~L}^{-1} \mathrm{NaCl}$ was used to adjust the ionic strength of the aqueous solutions. All other reagents and solvents were of analytical reagent grade and used without further purification unless otherwise noted. All aqueous solutions were prepared using newly double-distilled water.

\subsection{Scheme}

The composition of precipitate was determined by the JobAsmus method [26]. The molar ratio tinidazole: TPB was found to be $1: 1$. It is possible that stronger basic secondary amine group in the molecule of tinidazole was transferred to cationic ion and reacted with tetraphenylboron. The precipitation reaction may be as follows.

\subsection{Standard procedure}

An appropriate aliquot of tinidazole working solution was added to a mixture of $1.0 \mathrm{~mL}$ of tetraphenylboron sodium solution $\left(10.0 \mathrm{mg} \mathrm{mL}^{-1}\right)$, and $1.0 \mathrm{~mL}$ sulfuric acid $\left(0.18 \mathrm{~mol} \mathrm{~L}^{-1}\right)$ and diluted to $10 \mathrm{~mL}$ with water. After standing for five minutes later, the solution was scanned on the fluorophotometer in the region of 250 to $750 \mathrm{~nm}$ with $\Delta \lambda=$ $0 \mathrm{~nm}$. The obtained RLS spectrum was recorded and its intensity was measured at $569.5 \mathrm{~nm}$. The enhanced RLS intensity of tinidazole-TPB system was represented as $\Delta I=I-I_{0}$ ( $I$ and $I_{0}$ were the RLS intensities of the system with and without tinidazole). The operations were carried out at room temperature.
The HPLC separation was performed on Kromasil ODS column $(250 \mathrm{~mm} \times 4.6 \mathrm{~mm}, 5 \mu \mathrm{m}$, Hanbon Science \& Technology Co., Ltd) connected with a Zorbax SB- $\mathrm{C}_{18}$ guard column $(20 \mathrm{~mm} \times 4 \mathrm{~mm}, 5 \mu \mathrm{m})$. The mobile phase consisted of methanol and $0.1 \%$ acetic acid aqueous solution (20 : $80, \mathrm{v} / \mathrm{v}$ ) and the flow-rate was $1.0 \mathrm{~mL} / \mathrm{min}$. The volume of sample injected was $20 \mu \mathrm{L}$. The monitoring wavelength was $310 \mathrm{~nm}$. The column temperature was set at $25^{\circ} \mathrm{C}$.

\subsection{Sample}

The injections of tinidazole were diluted 100 to 200 folds with pure water. The tablets of tinidazole were dissolved in $500 \mathrm{~mL}$ pure water and filtered through a $0.45 \mu \mathrm{m}$ cellulose acetate membrane. A $1.0 \mathrm{~mL}$ aliquot of the prepared sample solutions was added to a $10 \mathrm{~mL}$ volumetric flask instead of tinidazole standard solution.

\section{RESULTS AND DISCUSSION}

\subsection{Characteristics of the RLS spectra}

The RLS spectrum of $\mathrm{B}\left(\mathrm{C}_{6} \mathrm{H}_{5}\right)_{4}-\mathrm{Na}$ in sulfuric acid solution $\left(0.018 \mathrm{~mol} \mathrm{~L}^{-1}\right)$ is shown in Figure 2b. It can be seen that the RLS intensity of $\mathrm{B}\left(\mathrm{C}_{6} \mathrm{H}_{5}\right)_{4}-\mathrm{Na}$ is quite weak in the whole scanning wavelength region. In contrast, upon addition of trace amount of tinidazole to $\mathrm{B}\left(\mathrm{C}_{6} \mathrm{H}_{5}\right)_{4}-\mathrm{Na}$ solution, a remarkably enhanced RLS with a maximum peak at $569.5 \mathrm{~nm}$ was observed under the same conditions (Figure 2, c-g). It can be clearly observed that there were two peaks located at 452.0 and $569.5 \mathrm{~nm}$ in the RLS spectrum of tinidazoleTPB system. The addition of increasing tinidazole to the $\mathrm{B}\left(\mathrm{C}_{6} \mathrm{H}_{5}\right)_{4}-\mathrm{Na}$ solution leads to the gradual enhancement in RLS intensity, exhibiting a concentration-dependent relationship. The production of RLS and its intensity are correlative with the formation of the aggregate and its particle dimension in solution [3].

As shown in Figures $2 a$ and $2 b$, when the RLS intensities of tinidazole and $\mathrm{NaB}\left(\mathrm{C}_{6} \mathrm{H}_{5}\right)_{4}$ were considered alone, they were quite weak. It thus can be concluded that $\mathrm{B}\left(\mathrm{C}_{6} \mathrm{H}_{5}\right)_{4}^{-}$ anion reacted with tinidazole and produced a new-formed compound whose RLS intensity was much higher than that of tinidazole or $\mathrm{NaB}\left(\mathrm{C}_{6} \mathrm{H}_{5}\right)_{4}$ when they existed separately. Moreover, the dimension of tinidazole-TPB particles may be much less than the incident wavelength, and thus the enhanced light-scattering signal occurs under the given conditions. In this way, the resonance light scattering formula [26] could be applicable to the tinidazole-TPB system.

\subsection{Effects of $p H$ values in medium}

The newly formed tinidazole-TPB compound may be ascribed to the higher electrostatic attraction between TPB and tinidazole than that of the coexistent sodium ion. Moreover, the RLS is relevant to the dimension of the formed aggregated species. Hence, the $\mathrm{pH}$ value may exert certain influence on the attraction strength and the dimension of suspension particles, and thus the RLS production and its intensity. As shown in Figure 3, the RLS intensity of $\mathrm{NaB}\left(\mathrm{C}_{6} \mathrm{H}_{5}\right)_{4}$ 
<smiles>c1ccc([B-](c2ccccc2)(c2ccccc2)c2ccccc2)cc1</smiles><smiles>CCOS(=O)(=O)CCn1c([N+](=O)[O-])cnc1C</smiles><smiles></smiles>

SCHEMe 1

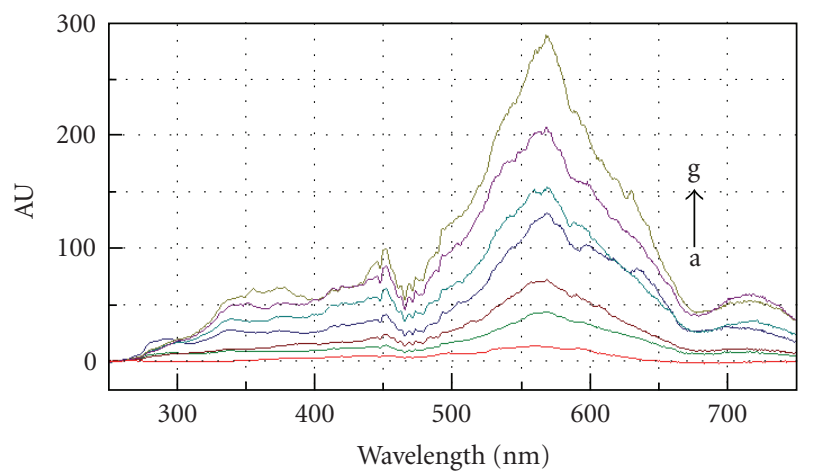

FIgURE 2: RLS spectra of five tinidazole-TPB systems: (a) tinidazole solution, $50 \mu \mathrm{g} \mathrm{mL} L^{-1}$; (b)-(g) $\mathrm{NaB}\left(\mathrm{C}_{6} \mathrm{H}_{5}\right)_{4} 1.0 \mathrm{mg} \mathrm{mL}^{-1}$, and sulfuric acid solution, $0.018 \mathrm{~mol} \mathrm{~L}^{-1}: 0,10,15,20,25,30 \mu \mathrm{g} \mathrm{mL}$ of tinidazole.

solution did not change with the variation of $\mathrm{pH}$ in range of 1.44-6.44, whereas that of the tinidazole-TPB system presented different traits. The RLS intensity of the tinidazole TPB decreased from $\mathrm{pH} 1.44$ to 6.44 . Acidity strongly affected the form of ammonium ion, which reacted with the $\mathrm{B}\left(\mathrm{C}_{6} \mathrm{H}_{5}\right)_{4}^{-}$. A maximum RLS intensity was obtained around $\mathrm{pH} 1.44$ and this value was selected for the subsequent measurements.

\subsection{Effect of ionic strength}

There existed high concentration of sodium chloride $(0.9 \%)$ in tinidazole samples such as injections. Did the large amounts of $\mathrm{Na}^{+}$and $\mathrm{Cl}^{-}$affect the RLS spectra of tinidazoleTPB system? The $\mathrm{Na}^{+}$and $\mathrm{Cl}^{-}$may interfere with the electrostatic attraction between TPB and tinidazole. Herein, sodium chloride was used to maintain the ionic strength of the solution. The unexpected observation is that both of the RLS intensity of TPB-Na and tinidazole-TPB system hardly changed with the concentration changes of added $\mathrm{NaCl}$ (Figure 4). Therefore, the system can be allowed in the solutions with high ionic strength such as injections.

\subsection{Addition orders}

The effect of addition order on the RLS intensity is listed in Table 1. It was found that the addition orders of reagents have

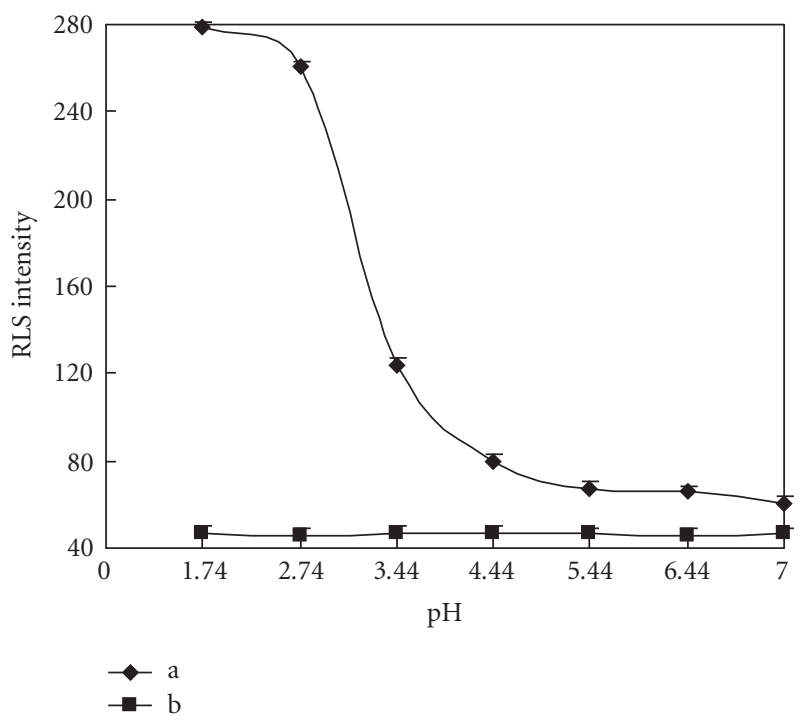

Figure 3: Effect of $\mathrm{pH}$ on the RLS intensity. (a) The tinidazoleTPB system suspension: $30 \mu \mathrm{g} \mathrm{mL}^{-1}$ of tinidazole, and $1 \mathrm{mg} \mathrm{mL}^{-1}$ of $\mathrm{NaB}\left(\mathrm{C}_{6} \mathrm{H}_{5}\right)_{4}$; (b) $1.0 \mathrm{mg} \mathrm{mL}^{-1}$ of $\mathrm{NaB}\left(\mathrm{C}_{6} \mathrm{H}_{5}\right)_{4}$.

no large effect on the RLS intensity. The proposed assay of tinidazole has a wide $\mathrm{pH}$ range.

\subsection{Stability}

The formation process of tinidazole-TPB particles includes three steps: nucleation, crystal growth, and aggregation, which will affect the sizes of the particles directly. Because the size of the particles is one important factor deciding RLS intensity, stabilizer must be used to control the size of particles, prevent the rapid sedimentation of the particles, and improve the reproducibility of RLS intensities of solutions. To improve the reproducibility of RLS intensity of a suspension system, it is crucial to impede the rapid sedimentation of the particles. In this regard, various stabilizers were usually used. However, tinidazole-TPB system is very stable within 20 minutes (Figure 5) and the average deviation of RLS signal was found to be lower than $2.28 \%$.

\subsection{Tolerance of foreign substances}

Some cationic and anionic species normally found in injections and tablets were studied by the addition of foreign 


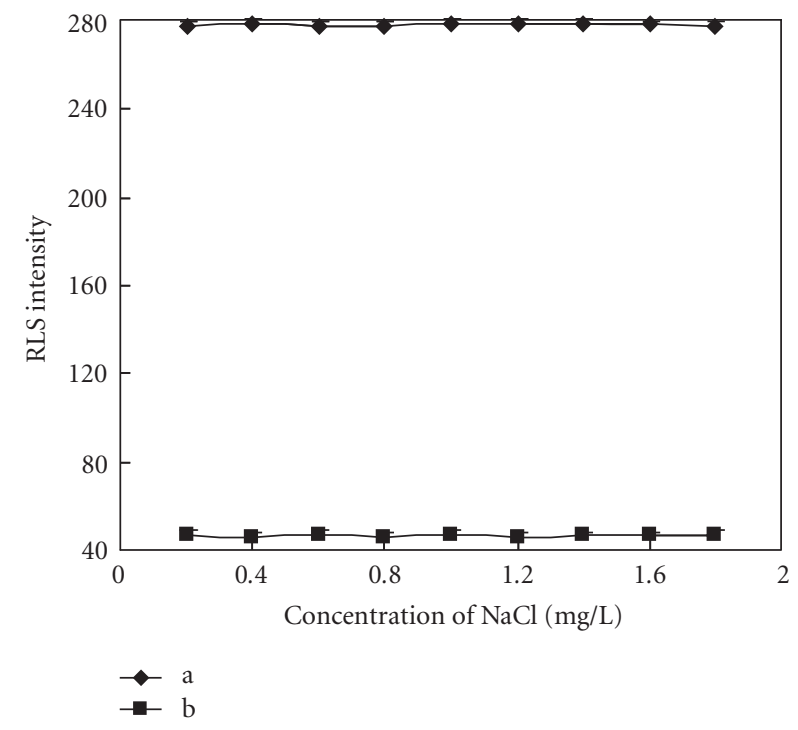

Figure 4: Effect of $\mathrm{NaCl}$ concentration on the RLS intensity. (a) The tinidazole-TPB system suspension: $30 \mu \mathrm{g} \mathrm{mL}^{-1}$ of tinidazole, $\mathrm{NaB}\left(\mathrm{C}_{6} \mathrm{H}_{5}\right)_{4} 1 \mathrm{mg} \mathrm{mL}^{-1}$, and sulfuric acid solution, $0.018 \mathrm{~mol} \mathrm{~L}^{-1}$; (b) the blank solution (without tinidazole).

TABLE 1: Effect of adding order.

\begin{tabular}{lccc}
\hline 1 & 2 & 3 & $\Delta I(\%)$ \\
\hline TPB & Tinidazole & Sulfuric acid & 100 \\
TPB & Sulfuric acid & Tinidazole & 97.19 \\
\hline Sulfuric acid & Tinidazole & TPB & 98.36 \\
\hline
\end{tabular}

substances. Their concentration relative to tinidazole and the corresponding influence to the determination are displayed in Table 2. Table 2 shows that few coexisting ions interfere with the determination of tinidazole. Common ions such as $\mathrm{Na}^{+}, \mathrm{Ca}^{2+}, \mathrm{Ba}^{2+}, \mathrm{Mg}^{2+}, \mathrm{Zn}^{2+}, \mathrm{Co}^{2+}, \mathrm{Cu}^{2+}, \mathrm{Al}^{3+}$, and $\mathrm{Pb}^{2+}$ can be tolerated at high concentrations because they did not combine with $\mathrm{B}\left(\mathrm{C}_{6} \mathrm{H}_{5}\right)_{4}^{-}$. However, some ions such as $\mathrm{K}^{+}$ and $\mathrm{NH}_{4}^{+}$can only be tolerated at very low concentration $\left(10 \mu \mathrm{g} \mathrm{mL}{ }^{-1}\right)$. In the studied species, $\mathrm{NH}_{4}^{+}$and $\mathrm{K}^{+}$were affected seriously due to similarity of ionic radius. However, $\mathrm{NH}_{4}^{+}$and $\mathrm{K}^{+}$were nearly absent in the sample, so it would not interfere with the determination. The most abundant $\mathrm{Na}^{+}$would interfere at the concentration of up to 1000 times than that of tinidazole. Because $\mathrm{Na}^{+}$was studied by adding $\mathrm{NaAc}$ and $\mathrm{Ac}^{-}$had more molecular weight than $\mathrm{Na}^{+}$, the tolerant level of $\mathrm{Ac}^{-}$was larger. The results demonstrated that the addition of $\mathrm{CO}_{3}^{2-}$ and $\mathrm{PO}_{4}^{3-}$ in excess of 1000 folds in concentration relative to tinidazole can induce moderate RLS signal. This may be due to the formation of extended aggregate around tinidazole-TPB particle cores by the relatively higher negatively charged ions of $\mathrm{CO}_{3}^{2-}$ and $\mathrm{PO}_{4}^{3-}$. Other studied ions have nearly no effects on the determination when their concentration was the same as or more than tinidazole. Due to the good selectivity of this method, assays can be performed without removing other coexisting ions.

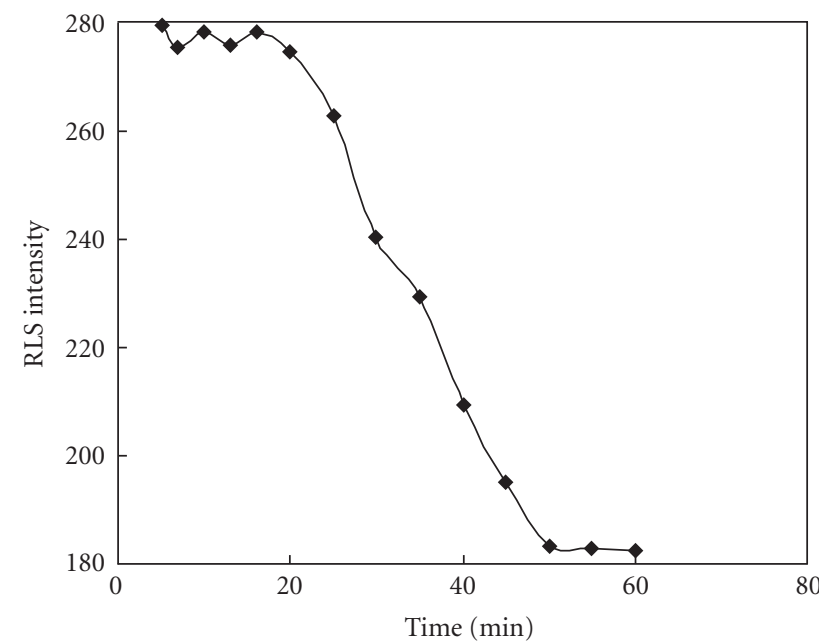

FIGURE 5: Stability of tinidazole-TPB system: $30 \mu \mathrm{g} \mathrm{mL}^{-1}$ of tinidazole, $\mathrm{NaB}\left(\mathrm{C}_{6} \mathrm{H}_{5}\right)_{4} 1 \mathrm{mg} \mathrm{mL}^{-1}$, and sulfuric acid solution $0.018 \mathrm{~mol} \mathrm{~L}^{-1}$.

\section{ANALYTICAL APPLICATIONS}

\subsection{Detection and quantification limits}

The detection limit was calculated as $s_{b}+3 s$, where $s_{b}$ is the average signal of ten blank solutions and $s$ the standard deviation. The quantification limit was calculated as $s_{b}+10 s$, where $s_{b}$ is the average RLS signal of ten blank solutions and $s$ the standard deviation. When the RLS intensity at $569.5 \mathrm{~nm}$ was selected, the detection limit and quantification limit were calculated to be $5.0 \mu \mathrm{g} \mathrm{mL}^{-1}$ and $10.0 \mu \mathrm{g} \mathrm{mL}^{-1}$, respectively, indicating high sensitivity of this method for the determination of tinidazole. The sensitivity of the RLS method is prominently higher than that of turbidimetry (results are not presented).

\subsection{Detected wavelength and calibration curves}

From the RLS spectra (Figure 2) of tinidazole-TPB system, three peaks are located at 452.0 and $569.5 \mathrm{~nm}$. The maximum RLS peak is located at $569.5 \mathrm{~nm}$. Calibration curves were determined for five different concentrations of tinidazole standard solutions under these two wavelengths. Each calibration sample was detected in triplicate. According to the above standard procedure, the calibration curves were obtained by plotting the concentration of tinidazole against the intensity of RLS spectra at 452.0 and $569.5 \mathrm{~nm}$ (Figure 6). Table 3 lists the parameters and correlation coefficients of the calibration plots with two wavelengths. The $\Delta I(y)$ and the tinidazole concentrations $(x)$ were fit to the linear function. The results of the regression analysis were then used to back-calculate the concentration results from the $\Delta I$, and the back-calculated concentrations and appropriate summary statistics (mean, standard deviation (SD), and percent relative standard deviation (RSD)) were calculated and presented in tabular form. 
TABLE 2: Effect of interfering ions on the tinidazole determination ${ }^{(a)}$.

\begin{tabular}{|c|c|c|c|c|c|}
\hline Foreign ion & $\begin{array}{l}\text { Ratio of the concentration } \\
\text { (foreign ions/[tinidazole]) }\end{array}$ & $\begin{array}{l}\text { Change in } \\
\text { RLS }(\%)\end{array}$ & Foreign ion & $\begin{array}{l}\text { Ratio of the concentration } \\
\text { (foreign ions/[tinidazole]) }\end{array}$ & $\begin{array}{l}\text { Change in } \\
\text { RLS }(\%)\end{array}$ \\
\hline$\overline{\mathrm{Na}^{+}}$ & 1000 & 1.54 & $\mathrm{NH}_{4}^{+}$ & 1 & 4.11 \\
\hline $\mathrm{Ca}^{2+}$ & 100 & 1.89 & $\mathrm{~Pb}^{2+}$ & 10 & 3.68 \\
\hline $\mathrm{Ba}^{2+}$ & 100 & 2.23 & $\mathrm{SO}_{4}^{2-}$ & 1000 & 0.87 \\
\hline $\mathrm{Mg}^{2+}$ & 100 & 1.59 & $\mathrm{NO}_{3}^{-}$ & 1000 & 0.94 \\
\hline $\mathrm{Zn}^{2+}$ & 100 & 3.42 & $\mathrm{CO}_{3}^{2-}$ & 1000 & 4.12 \\
\hline $\mathrm{Co}^{2+}$ & 100 & 2.46 & $\mathrm{SO}_{3}^{2-}$ & 1000 & 1.53 \\
\hline $\mathrm{Cu}^{2+}$ & 100 & 4.15 & $\mathrm{PO}_{4}^{3-}$ & 1000 & 3.91 \\
\hline $\mathrm{Al}^{3+}$ & 100 & 3.76 & $\mathrm{Cl}^{-}$ & 1000 & 0.71 \\
\hline $\mathrm{K}^{+}$ & 1 & 4.28 & $\mathrm{Ac}^{-}$ & 1000 & 1.54 \\
\hline
\end{tabular}

(a) The cationic ions were added in the form of chloride, and the anionic ions were added in the form of sodium.

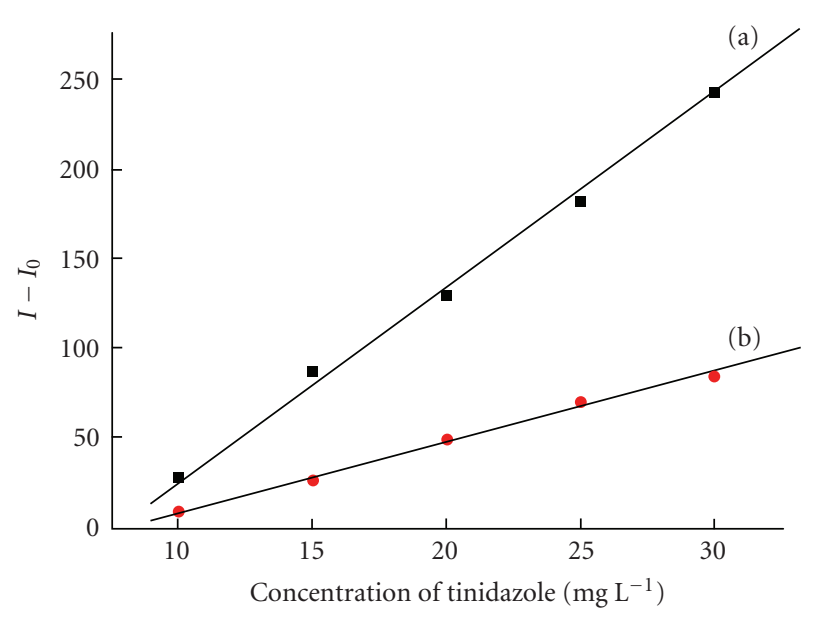

FIgURE 6: Relationships between RLS intensities of tinidazole-TPB system and the detected wavelengths. ((a) $\lambda=569.5 \mathrm{~nm}$, (b) $\lambda=$ $452.0 \mathrm{~nm})$.

From Table 3, detected wavelength has obvious effect on the linear relationship of this method. To different detected wavelength, the RLS intensity of the system is also different. It offers a wide detected range for different concentration of tinidazole in samples. The lowest detection limit and quantification limit took place at $569.5 \mathrm{~nm}$, because $569.5 \mathrm{~nm}$ is the maximum RLS peak.

\subsection{Precision}

The precision study was comprised of repeatability and reproducibility studies. These were developed in five different samples. The repeatability was established by analyzing the samples five times. The reproducibility was determined by analyzing each sample on three different days over about one month. The repeatability and the reproducibility are $<2.37 \%$ and $<3.96 \%$, respectively. These results indicate that the present method can be used for quantitative analyses of tinidazole.
TABle 3: Effect of wavelengths on the linear relationship ${ }^{(a)}$.

\begin{tabular}{lll}
\hline Wavelength $(\mathrm{nm})$ & $\begin{array}{l}\text { Linear regression } \\
\text { equation }\end{array}$ & Correlation coefficient \\
\hline 452.0 & $y=-29.308+3.8868 x$ & 0.9958 \\
569.5 & $y=-75.356+10.472 x$ & 0.9962 \\
\hline
\end{tabular}

(a) $y$ is $\Delta I ; x$ is the tinidazole concentrations $\left(\mu \mathrm{g} \mathrm{mL}^{-1}\right)$.

\subsection{Recovery}

To establish the accuracy of the method, this procedure was also performed on tinidazole added to samples. Table 4 shows the recoveries of tinidazole applying this analytical method. From Table 4, good results are obtained with the recovery range of $95.13-106.76 \%$.

\subsection{Comparison of RLS and HPLC methods}

As shown in Table 5, the proposed method was applied to determine tinidazole concentration in injections and tablets. The attained results were compared with that of HPLC method. From Table 5, it was seen that the RLS results were in agreement with the HPLC method according to Chinese Pharmacopoeia. The average RSD of the RLS method is $0.79 \%-1.83 \%$, which is slightly lower than that of the HPLC method (1.22\%-2.48\%), which proved that the RLS assay of tinidazole in drugs was practical.

In this paper, we compared two methods to analyze tinidazole in injections and tablets. These two methods, RLS and HPLC, can give similar results for tinidazole content in drugs (Table 5). However, the operations of RLS and HPLC methods were significantly different. The HPLC method appears to suffer from complexity and cost time, whereas the RLS method described here is robust, cost effective, and simple while retaining sufficient sensitivity. It took more than 10 minutes for an HPLC analysis, but only 1 minute for RLS analysis. Second, the RLS analysis was not affected by small variation in temperature, so it could be carried out at room temperature. But the temperature had a significant effect on the HPLC analysis. The HPLC column temperature was set 
TABLE 4: Recovery tests of some samples.

\begin{tabular}{l|ccccc}
\hline Sample & Tinidazole in samples $(\mu \mathrm{g})$ & Added $(\mu \mathrm{g})$ & Found $(\mu \mathrm{g})$ & Recovery range $(\%)$ & RSD $(\%)(n=5)$ \\
\hline 1 & 101.45 & 100 & $196.58-206.03$ & $95.13-104.58$ & 2.81 \\
2 & 101.83 & 100 & $202.35-207.32$ & $100.17-105.49$ & 2.11 \\
3 & 202.44 & 200 & $395.97-398.71$ & $96.77-98.14$ & 1.94 \\
4 & 25.16 & 25 & $51.08-51.85$ & $104.08-106.76$ & 3.42 \\
5 & 24.85 & 25 & $49.21-50.68$ & $97.44-103.32$ & 3.36 \\
\hline
\end{tabular}

TABle 5: Determination results of tinidazole in samples ${ }^{(a)}$.

\begin{tabular}{|c|c|c|c|c|c|c|}
\hline \multicolumn{2}{|c|}{ Samples } & \multirow{2}{*}{$\begin{array}{c}\text { Labeled amount } \\
2000 \mu \mathrm{g} \mathrm{mL}^{-1}\end{array}$} & \multirow{2}{*}{$\begin{array}{c}\text { RLS technique }(n=5) \\
2029.39 \mu \mathrm{g} \mathrm{mL}^{-1}\end{array}$} & \multirow{2}{*}{$\frac{\mathrm{RSD}(\%)}{1.59}$} & \multirow{2}{*}{$\begin{array}{c}\text { HPLC method }(n=5) \\
2054.13 \mu \mathrm{g} \mathrm{mL}^{-1}\end{array}$} & \multirow{2}{*}{$\begin{array}{c}\text { RSD (\%) } \\
1.89\end{array}$} \\
\hline 1 & Injection & & & & & \\
\hline 2 & Injection & $2000 \mu \mathrm{g} \mathrm{mL}^{-1}$ & $2036.54 \mu \mathrm{g} \mathrm{mL}^{-1}$ & 1.22 & $2041.31 \mu \mathrm{g} \mathrm{mL}^{-1}$ & 2.09 \\
\hline 3 & Injection & $4000 \mu \mathrm{g} \mathrm{mL}^{-1}$ & $4048.68 \mu \mathrm{g} \mathrm{mL}^{-1}$ & 1.67 & $4069.27 \mu \mathrm{g} \mathrm{mL}^{-1}$ & 1.54 \\
\hline 4 & Injection & $4000 \mu \mathrm{g} \mathrm{mL}^{-1}$ & $4019.23 \mu \mathrm{g} \mathrm{mL}^{-1}$ & 1.83 & $4045.09 \mu \mathrm{g} \mathrm{mL}^{-1}$ & 2.71 \\
\hline 5 & Vaginal effervescent tablets & $250 \mathrm{mg} / \mathrm{tablet}$ & $248.35 \mathrm{mg} /$ tablet & 0.79 & $249.18 \mathrm{mg} /$ tablet & 1.22 \\
\hline 6 & Vaginal effervescent tablets & $250 \mathrm{mg} /$ tablet & $251.62 \mathrm{mg} /$ tablet & 1.04 & $252.04 \mathrm{mg} / \mathrm{tablet}$ & 2.14 \\
\hline 7 & Vaginal effervescent tablets & $250 \mathrm{mg} /$ tablet & $251.09 \mathrm{mg} /$ tablet & 1.47 & $251.65 \mathrm{mg} / \mathrm{tablet}$ & 2.48 \\
\hline
\end{tabular}

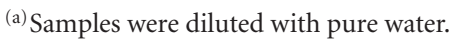

at a fixed temperature. Third, the RLS analysis did not use organic solvent, but toxic acetonitrile is used in the HPLC analysis.

\subsection{Mechanism discussion}

Light scattering is caused by the presence of fine particles. Because the dimension of tinidazole-TPB particles is much less than the incident wavelength, it should be in accordance with the resonance light scattering formula, which is shown as follows [27]:

$$
R(\theta)=\frac{9 \pi^{2}}{2 \lambda^{4}}\left(\frac{n_{1}^{2}-n_{0}^{2}}{n_{1}^{2}+2 n_{0}^{2}}\right)^{2} N_{0} v^{2}\left(1+\cos ^{2} \theta\right),
$$

where $R(\theta)$ is the resonance light ratio at the scattering angle $\theta$, which is equal to the ratio of the scattering intensity of incident light $I(\theta)$ at the angle $\theta$ to the intensity of incident light $I_{0} ; n_{1}$ and $n_{0}$ are the refractive indices of solute and medium, respectively; $N_{0}$ is the number of particles per unit volume; $v$ is the volume of the particle; and $\lambda$ is the wavelength of incident light in the medium.

If $c$ is the concentration of tinidazole-TPB solution, and $\rho$ is the density of each particle, so $N_{0} v$ is equal to $c / \rho$. The formula above can be expressed as

$$
R(\theta)=\frac{9 \pi^{2}}{2 \lambda^{4}}\left(\frac{n_{1}^{2}-n_{0}^{2}}{n_{1}^{2}+2 n_{0}^{2}}\right)^{2} \frac{c}{\rho} v\left(1+\cos ^{2} \theta\right) .
$$

In the experiment, $\theta$ is $90^{\circ}, v$ remained nearly constant because the experiment conditions such as acidity and the adding volume of stabilizer and other reagents were kept as identical as possible to obtain the same size particles; $n_{1}, n_{0}$, $\lambda$, and $\rho$ were all constant. According to (2), RLS intensity is proportional to the concentration of tinidazole-TPB suspen- sion $(c)$ or the number of particles in the unit volume $\left(N_{0}\right)$. Therefore, tinidazole can be determined based on this theory.

\section{CONCLUSION}

In this contribution, we proposed a resonance light scattering technique to determine tinidazole in drugs. The analytical results showed that our method is rapid, sensitive, selective, and potential to be put into practice. This method may also be a valuable approach for the development of detection of tinidazole in serum.

\section{ACKNOWLEDGMENT}

The authors show their appreciation to Hunan Wantwant Hospital for their kindness in providing the samples of tinidazole injections and tablets.

\section{REFERENCES}

[1] S. C. Sweetman, Martindale: The Complete Drug Reference, Pharmaceutical Press, London, UK, 2002.

[2] H. Salomies, "Structure elucidation of the photolysis and hydrolysis products of tinidazole," Acta Pharmaceutica Nordica, vol. 3, no. 4, pp. 211-214, 1991.

[3] R. F. Pasternack, C. Bustamante, P. J. Collings, A. Giannetto, and E. J. Gibbs, "Porphyrin assemblies on DNA as studied by a resonance light-scattering technique," Journal of the American Chemical Society, vol. 115, no. 13, pp. 5393-5399, 1993.

[4] R. F. Pasternack and P. J. Collings, "Resonance light scattering: a new technique for studying chromophore aggregation," Science, vol. 269, no. 5226, pp. 935-939, 1995.

[5] P. J. Collings, E. J. Gibbs, T. E. Starr, et al., "Resonance light scattering and its application in determining the size, shape, and aggregation number for supramolecular assemblies of chromophores," Journal of Physical Chemistry B, vol. 103, no. 40 , pp. 8474-8481, 1999. 
[6] Z. De Liu, C. Z. Huang, Y. F. Li, and Y. F. Long, "Enhanced plasmon resonance light scattering signals of colloidal gold resulted from its interactions with organic small molecules using captopril as an example," Analytica Chimica Acta, vol. 577, no. 2, pp. 244-249, 2006.

[7] Z. Chen, J. Liu, Y. Han, and L. Zhu, "A novel histidine assay using tetraphenylporphyrin manganese (III) chloride as a molecular recognition probe by resonance light scattering technique," Analytica Chimica Acta, vol. 570, no. 1, pp. 109$115,2006$.

[8] C. Z. Huang, W. Lu, Y. F. Li, and Y. M. Huang, "On the factors affecting the enhanced resonance light scattering signals of the interactions between proteins and multiply negatively charged chromophores using water blue as an example," Analytica Chimica Acta, vol. 556, no. 2, pp. 469-475, 2006.

[9] Y. J. Long, Y. F. Li, and C. Z. Huang, "A wide dynamic range detection of biopolymer medicines with resonance light scattering and absorption ratiometry," Analytica Chimica Acta, vol. 552, no. 1-2, pp. 175-181, 2005.

[10] Z. Chen, W. Ding, F. L. Ren, J. Liu, and Y. Liang, "A simple and sensitive assay of nucleic acids based on the enhanced resonance light scattering of zwitterionics," Analytica Chimica Acta, vol. 550, no. 1-2, pp. 204-209, 2005.

[11] C. Z. Huang and Y. F. Li, "Resonance light scattering technique used for biochemical and pharmaceutical analysis," Analytica Chimica Acta, vol. 500, no. 1-2, pp. 105-117, 2003.

[12] J. B. Xiao, C. S. Yang, F. L. Ren, X. Y. Jiang, and M. Xu, "Rapid determination of ciprofloxacin lactate in drugs by the Rayleigh light scattering technique," Measurement Science and Technology, vol. 18, no. 3, pp. 859-866, 2007.

[13] Q. Wei, H. Zhang, B. Du, Y. Li, and X. Zhang, "Sensitive determination of DNA by resonance light scattering with pentamethoxyl red," Microchimica Acta, vol. 151, no. 1-2, pp. 5965, 2005.

[14] Z. Chen, W. Ding, Y. Liang, F. L. Ren, Y. Han, and J. Liu, "Determination of nucleic acids based on their resonance light scattering enhancement effect on metalloporphyrin derivatives," Microchimica Acta, vol. 150, no. 1, pp. 35-42, 2005.

[15] Z. Chen, T. Zhang, F. L. Ren, and W. Ding, "Determination of proteins at nanogram levels based on their resonance light scattering decrease effect on the dibromo-onitrophenylfluorone-sodium lauroyl glutamate system," $\mathrm{Mi}$ crochimica Acta, vol. 153, no. 1-2, pp. 65-71, 2006.

[16] Y. Zhou, S. She, L. Zhang, and Q. Lu, "Determination of proteins at nanogram levels using the resonance light scattering technique with a novel PVAK nanoparticle," Microchimica Acta, vol. 149, no. 1-2, pp. 151-156, 2005.

[17] J. B. Xiao, J. W. Chen, F. L. Ren, Y. Y. Chen, and M. Xu, "Highly sensitive detection of trace potassium ion in serum using resonance light scattering technique with sodium tetraphenylboron," to appear in Microchimica Acta.

[18] J. B. Xiao, J. W. Chen, F. L. Ren, C. S. Yang, and M. Xu, "Use of 3-(4,5-dimethylthiazol-2-yl)-2,5-diphenyl tetrazolium bromide for rapid detection of methicillin-resistant Staphylococcus aureus by resonance light scattering," Analytica Chimica Acta, vol. 589, no. 2, pp. 186-191, 2007.

[19] K. Rajnarayana, M. R. Chaluvadi, V. R. Alapati, S. R. Mada, G. Jayasagar, and D. R. Krishna, "Validated HPLC method for the determination of tinidazole in human serum and its application in a clinical pharmacokinetic study," Pharmazie, vol. 57, no. 8, pp. 535-537, 2002.

[20] M. Bakshi and S. Singh, "HPLC and LC-MS studies on stress degradation behaviour of tinidazole and development of a validated specific stability-indicating HPLC assay method," Jour- nal of Pharmaceutical and Biomedical Analysis, vol. 34, no. 1, pp. 11-18, 2004.

[21] L. Zhang, Z. Zhang, and $\mathrm{K}$. Wu, "In vivo and real time determination of ornidazole and tinidazole and pharmacokinetic study by capillary electrophoresis with microdialysis," Journal of Pharmaceutical and Biomedical Analysis, vol. 41, no. 4, pp. 1453-1457, 2006.

[22] P. Nagaraja, K. R. Sunitha, R. A. Vasantha, and H. S. Yathirajan, "Spectrophotometric determination of metronidazole and tinidazole in pharmaceutical preparations," Journal of Pharmaceutical and Biomedical Analysis, vol. 28, no. 3-4, pp. 527-535, 2002.

[23] C. Yang, "Voltammetric determination of tinidazole using a glassy carbon electrode modified with single-wall carbon nanotubes," Analytical Sciences, vol. 20, no. 5, pp. 821-824, 2004.

[24] A. Z. Abu Zuhri, S. Al-Khalil, R. M. Shubietah, and I. El-Hroub, "Electrochemical study on the determination of tinidazole in tablets," Journal of Pharmaceutical and Biomedical Analysis, vol. 21, no. 4, pp. 881-886, 1999.

[25] S. A. Özkan, Y. Özkan, and Z. Şentürk, "Electrochemical reduction of metronidazole at activated glassy carbon electrode and its determination in pharmaceutical dosage forms," Journal of Pharmaceutical and Biomedical Analysis, vol. 17, no. 2, pp. 299-305, 1998.

[26] S. K. Sindhwani and R. P. Singh, "Spectrophotometric determination of osmium using acenaphthenequinonemonoxime," Microchemical Journal, vol. 18, no. 6, pp. 627-635, 1973.

[27] S. Z. Zhang, F. L. Zhao, K. A. Li, and S. Y. Tong, "A study on the interaction between concanavalin A and glycogen by light scattering technique and its analytical application," Talanta, vol. 54, no. 2, pp. 333-342, 2001. 


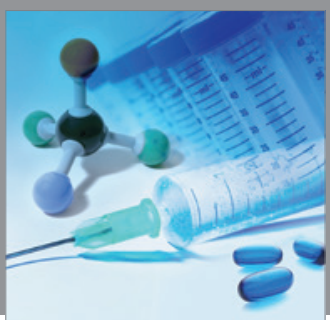

International Journal of

Medicinal Chemistry

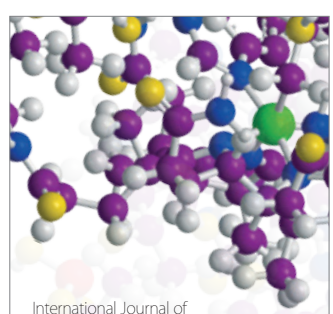

Carbohydrate Chemistry

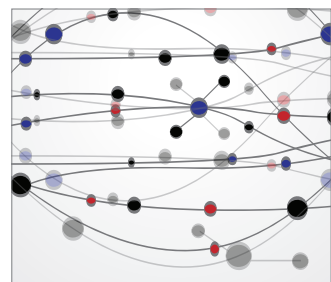

The Scientific World Journal
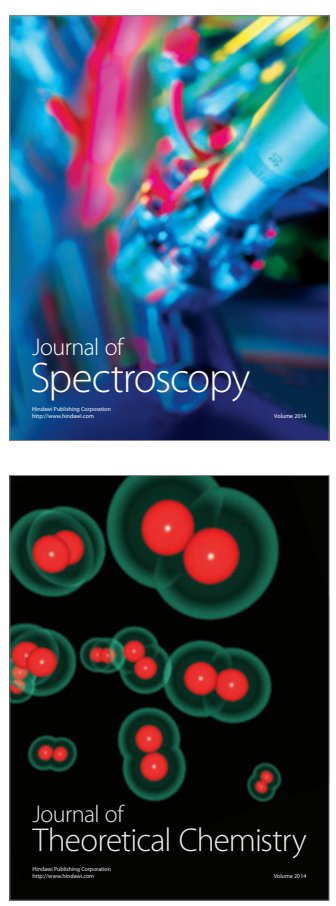
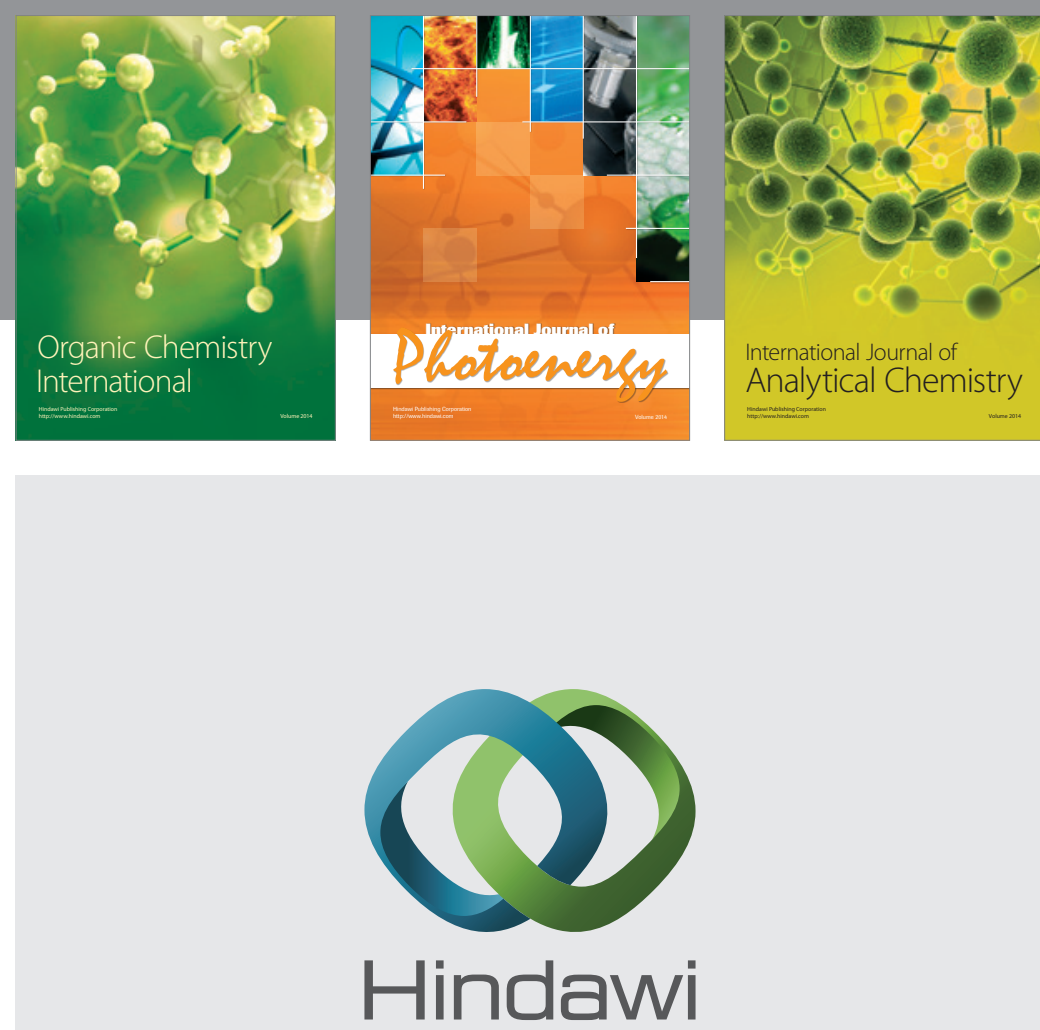

Submit your manuscripts at

http://www.hindawi.com
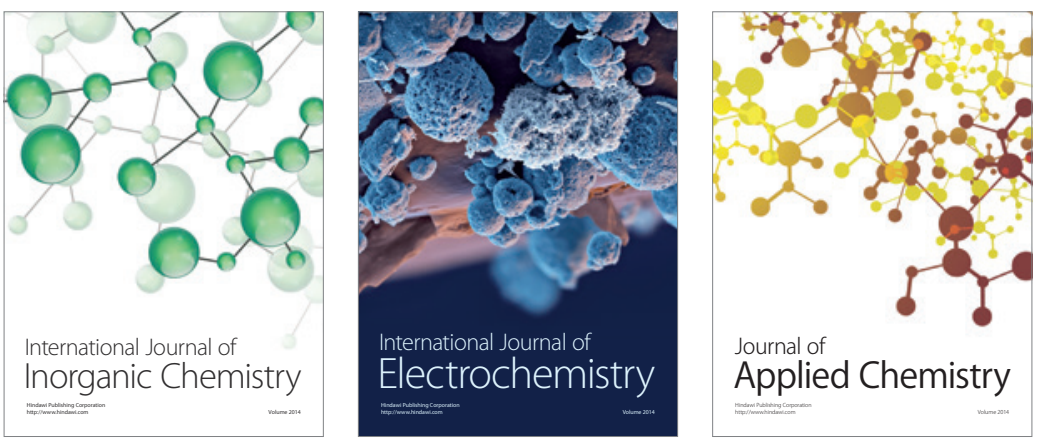

Journal of

Applied Chemistry
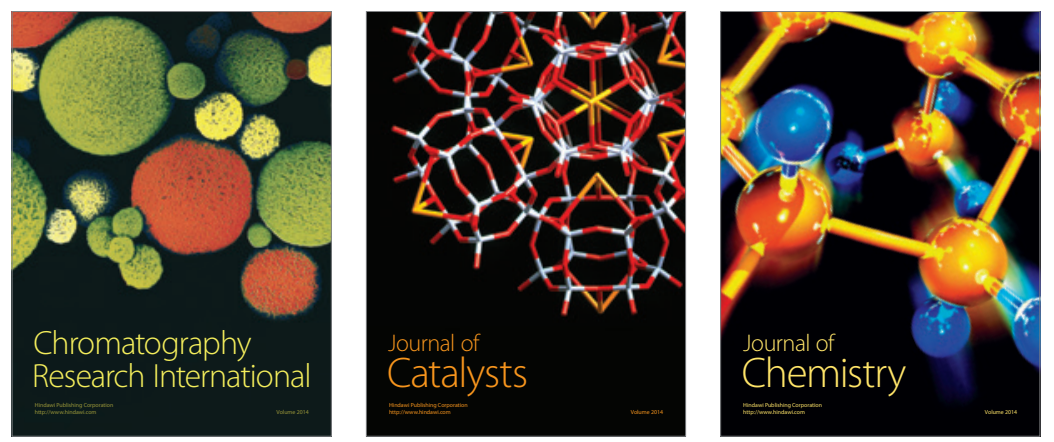
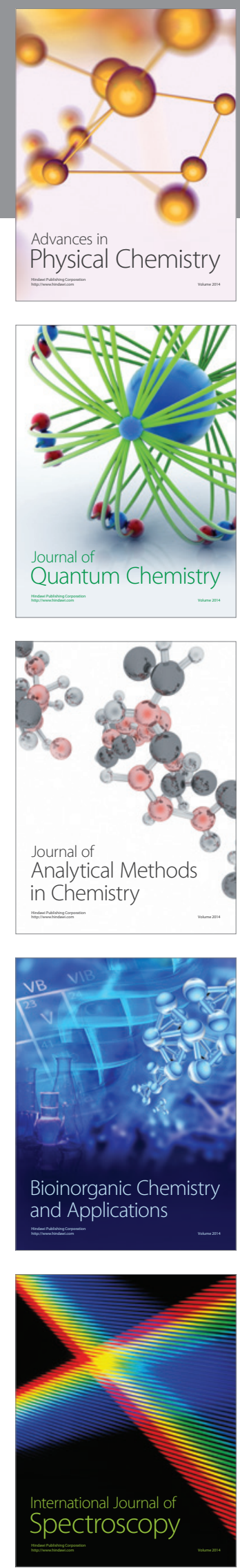